\title{
Risk of sexual transmitted infection following Pesearch Paper Risk of sexual transmitted infection following bipolar disorder: a nationwide population-based cohort study
}

\author{
Shyh-Chyang Lee ${ }^{2,3, *}$, Chang-Kuo Hu, ${ }^{4, *}$, Jeng-Hsiu Hung ${ }^{5,6}$, Albert C. Yang ${ }^{7,8,9}$, Shih- \\ Jen Tsai ${ }^{7,9}$, Min-Wei Huang ${ }^{10}$, Li-Yu Hu ${ }^{1,9}$ and Cheng-Che Shen ${ }^{9,10}$ \\ ${ }^{1}$ Department of Psychiatry \& Center for Geriatrics and Gerontology, Kaohsiung Veterans General Hospital, Kaohsiung, Taiwan \\ ${ }^{2}$ Department of Orthopedics, Chiayi Branch, Taichung Veterans General Hospital, Chiayi, Taiwan \\ ${ }^{3}$ Department of Information Management, Chia Nan University of Pharmacy and Science, Tainan, Taiwan \\ ${ }^{4}$ Division of Neurosurgery, Department of Surgery, Chiayi Branch, Taichung Veterans General Hospital, Chiayi, Taiwan \\ ${ }^{5}$ Department of Obstetrics and Gynecology, Taipei Tzu Chi Hospital, Buddhist Tzu Chi Medical Foundation, New Taipei City, Taiwan \\ ${ }^{6}$ School of Medicine, Tzu Chi University, Hualien, Taiwan \\ ${ }^{7}$ Department of Psychiatry, Taipei Veterans General Hospital, Taipei, Taiwan \\ ${ }^{8}$ Center for Dynamical Biomarkers and Translational Medicine, National Central University, Chungli, Taiwan \\ ${ }^{9}$ School of Medicine, National Yang-Ming University, Taipei, Taiwan \\ ${ }^{10}$ Department of Psychiatry, Chiayi Branch, Taichung Veterans General Hospital, Chiayi, Taiwan \\ *These authors contributed equally to this work \\ Correspondence to: Li-Yu Hu, email: lyhu@vghks.gov.tw \\ Cheng-Che Shen, email: pures1000@yahoo.com.tw
}

Keywords: bipolar disorder; sexually transmitted infection; epidemiology; public health; nationwide study

Received: December 04, $2017 \quad$ Accepted: February 25, $2018 \quad$ Published: April 03, 2018

Copyright: Lee et al. This is an open-access article distributed under the terms of the Creative Commons Attribution License 3.0 (CC BY 3.0), which permits unrestricted use, distribution, and reproduction in any medium, provided the original author and source are credited.

\section{ABSTRACT}

Background: Bipolar disorder is a severe mental disorder associated with functional and cognitive impairment. Numerous studies have investigated associations between sexually transmitted infections (STIs) and psychiatric illnesses. However, the results of these studies are controversial.

Objective: We explored the association between bipolar disorder and the subsequent development of STIs, including human immunodeficiency virus infection; primary, secondary, and latent syphilis; genital warts; gonorrhea; chlamydial infection; and trichomoniasis.

Results: The bipolar cohort consisted of 1293 patients, and the comparison cohort consisted of $\mathbf{5 1 7 2}$ matched control subjects without bipolar disorder. The incidence of subsequent STIs (hazard ratio $(H R)=2.23,95 \%$ confidence interval $(\mathrm{CI}) \mathbf{1 . 6 8 - 2 . 9 6}$ ) was higher among the patients with bipolar disorder than in the comparison cohort. Furthermore, female gender is a risk factor for acquisition of STIs (HR $=2.36,95 \%$ CI 1.73-4.89) among patients with bipolar disorder. For individual STIs, the results indicated that the patients with bipolar disorder exhibited a markedly higher risk for subsequently contracting syphilis, genital warts, and trichomoniasis.

Conclusions: Bipolar disorder might increase the risk of subsequent newly diagnosed STIs, including syphilis, genital warts, and trichomoniasis. Clinicians should pay particular attention to STIs in patients with bipolar disorder. Patients with bipolar disorder, especially those with a history of high-risk sexual behaviors, should be routinely screened for STIs.

Methods: We identified patients who were diagnosed with bipolar disorder in the Taiwan National Health Insurance Research Database. A comparison cohort was 


\section{constructed of patients without bipolar disorder who were matched with the bipolar cohort according to age and gender. The occurrence of subsequent new-onset STIs was evaluated in both cohorts.}

\section{INTRODUCTION}

Bipolar disorder is a severe mental disorder associated with functional and cognitive impairment [1-3] and increased risk of suicide [4]. The lifetime prevalence of bipolar disorder is $2.1 \%$ in the general population [5], and bipolar disorder is the sixth leading cause of disability worldwide [6]. Bipolar disorder is characterized by the presence of manic or hypomanic episodes, often alternating with depressive episodes [7]. The manic or hypomanic episodes of bipolar disorder are characterized by symptoms including elated mood, increased energy, grandiosity, decreased need for sleep, impulsivity, and hypersexuality [7], and these symptoms often lead to risky behaviors, including risky sexual behaviors.

Sexually transmitted infections (STIs) are infections that are commonly spread through sexual behaviors. In 2015, approximately 1.1 billion people had STIs other than human immunodeficiency virus (HIV) infection [3], and such STIs resulted in 108,000 deaths in 2015 [8]. In the United States, millions of cases of STIs occur each year, resulting in substantial medical costs. A study indicated that the total lifetime direct medical cost for STIs in 2008 in the United States was $\$ 15.6$ billion and that the burden of STIs would be even greater in the absence of STI prevention and control efforts [9]. Therefore, it is essential to identify the risk factors of STIs and arrange appropriate screening protocols for people with risk factors.

Numerous studies have described associations between STIs and psychiatric illnesses [10-18]. However, most of these studies were focused on HIV infection only, and few studies have been designed to investigate the associations between psychiatric illness and other STIs, such as syphilis, genital warts, gonorrhea, chlamydial infection, and trichomoniasis [10, 17]. Also, the results of these studies are controversial. For example, a study in the United States revealed that HIV infection was present in $1.2 \%$ of the psychiatric outpatients, approximately four times the occurrence of HIV infection in the general adult population [11]. However, another study in the United States demonstrated that the odds of new HIV infection among beneficiaries with or without severe mental illness did not differ significantly [14]. Furthermore, most of these study results were based on cross-sectional study designs and lacked a longitudinal perspective [10-13, 15-18].

In response to the lack of longitudinal studies concerning the association between bipolar disorder and the subsequent risk of STIs and on the basis of the hypothesis that bipolar disorder, a severe psychiatric illness related to hypersexuality and risky behaviors, might be associated with a higher risk for developing subsequent STIs, we designed a nationwide population- based retrospective cohort study to investigate the possible link between these two illnesses.

\section{RESULTS}

Our study sample comprised 1293 patients with bipolar disorder and 5172 control subjects without bipolar disorder. The demographic and clinical variables of the bipolar and control cohorts are compared in Table 1. The median age of the patients was 42.3 years (interquartile range, 30.9-56.3 y), and the median follow-up durations of the bipolar and control cohorts were 10.68 and 11.02 years, respectively. A higher percentage of patients with bipolar disorder were observed in the group of people aged 20-39 years. The baseline difference in comorbidities demonstrated a higher prevalence of hypertension, diabetes mellitus, dyslipidemia, coronary artery disease, congestive heart failure, chronic pulmonary disease, and cerebrovascular disease among the patients with bipolar disorder. During the follow-up period, 75 (5.80\%) patients with bipolar disorder and $140(2.71 \%)$ control patients were diagnosed with sexually transmitted diseases $(P<.001)$. The most common subsequent sexually transmitted diseases in the patients with bipolar disorder were trichomoniasis in 28 patients $(2.17 \%)$, genital warts in 14 patients $(1.08 \%)$, and chlamydial infection in 13 patients (1.08\%). Overall, significantly higher incidences of syphilis [11 $(0.85 \%)$ versus $12(0.23 \%), P<.001]$, genital warts [14 $(1.08 \%)$ versus $13(0.25 \%), P<.001]$, and trichomoniasis [28 (2.17\%) versus $57(1.10 \%)$, $P=.006]$ were observed in the patients with bipolar disorder than in the control patients.

A subanalysis based on the duration of follow-up revealed that most of the STIs developed beyond the first year following a bipolar diagnosis and that the risk of syphilis, genital warts, and trichomoniasis remained significantly elevated when the patients diagnosed with STIs within 1 year of bipolar diagnosis were excluded. The results of the subanalysis are summarized in Table 2.

In addition, a Cox proportional hazards regression analysis was conducted to calculate the HR of new STI diagnosis for the patients with bipolar disorder compared with the matched control subjects. The results revealed that patients with bipolar disorder exhibited a markedly higher risk for subsequent STIs ( $\mathrm{HR}=2.23,95 \%$ confidence interval (CI) 1.68-2.96; Table 3). Furthermore, among patients with bipolar disorder, female gender was a risk factor for acquisition of STIs compared with male gender $(\mathrm{HR}=2.36,95 \%$ CI 1.77-3.16; Table 4). For individual STIs, the results indicated that the patients with bipolar disorder exhibited a markedly higher risks of subsequent syphilis $(\mathrm{HR}=3.99,95 \%$ CI $1.72-9.28)$, genital warts 
Table 1: Characteristics of bipolar disorder and sexually transmitted diseases (STIs) and control subjects

\begin{tabular}{|c|c|c|c|}
\hline & Bipolar disorder & Control cohort & $P$ values \\
\hline No. & 1,293 & 5,172 & \\
\hline Age $(\text { years })^{\mathrm{a}}$ & $42.3(30.9-56.3)$ & $42.3(30.9-56.3)$ & $>.999$ \\
\hline \multicolumn{4}{|l|}{ Distribution of age } \\
\hline $20-39$ & $574(44.39)$ & $2,296(44.39)$ & \\
\hline $40-64$ & $512(39.60)$ & $2,048(39.60)$ & \\
\hline$\geq 65$ & $207(16.00)$ & $828(16.00)$ & \\
\hline Gender & & & $>.999$ \\
\hline Female & $636(49.19)$ & 2,544 (49.19) & \\
\hline Male & $657(50.81)$ & $2,628(50.81)$ & \\
\hline \multicolumn{4}{|l|}{ Comorbidities } \\
\hline Hypertension & $380(29.39)$ & $1,115(21.56)$ & $<.001^{*}$ \\
\hline Diabetes mellitus & $233(18.02)$ & $664(12.84)$ & $<.001^{*}$ \\
\hline Dyslipidemia & $238(18.41)$ & $820(15.85)$ & $.029^{*}$ \\
\hline Coronary artery disease & $234(18.10)$ & $671(12.97)$ & $<.001^{*}$ \\
\hline Congestive heart failure & $59(4.56)$ & $143(2.76)$ & $.002^{*}$ \\
\hline Cerebrovascular disease & $212(16.40)$ & $476(9.20)$ & $<.001^{*}$ \\
\hline Chronic pulmonary disease & $205(15.85)$ & $543(10.50)$ & $<.001^{*}$ \\
\hline Income & & & $<.001^{*}$ \\
\hline High income & $108(8.35)$ & $583(11.27)$ & \\
\hline Medium income & $197(15.24)$ & $1,001(19.35)$ & \\
\hline Low income & $721(55.76)$ & $2,554(49.38)$ & \\
\hline No income & $267(20.65)$ & $1,034(19.99)$ & \\
\hline Degree of urbanization & & & $<.001^{*}$ \\
\hline Urban & $687(53.13)$ & $3,113(60.19)$ & \\
\hline Suburban & $396(30.63)$ & $1,692(32.71)$ & \\
\hline Rural & $210(16.24)$ & $367(7.10)$ & \\
\hline Newly diagnosed STI, n (\%) & $75(5.80)$ & $140(2.71)$ & $<.001^{*}$ \\
\hline HIV infection & $5(0.39)$ & $6(0.12)$ & 0.050 \\
\hline Syphilis & $11(0.85)$ & $12(0.23)$ & $<.001^{*}$ \\
\hline Genital warts & $14(1.08)$ & $13(0.25)$ & $<.001^{*}$ \\
\hline Gonorrhea & $8(0.62)$ & $23(0.44)$ & .376 \\
\hline Chlamydial infection & $13(1.01)$ & $33(0.64)$ & .193 \\
\hline Trichomoniasis & $28(2.17)$ & $57(1.10)$ & $.006^{*}$ \\
\hline Follow-up, years ${ }^{\mathrm{a}}$ & $10.68(9.20-12.38)$ & $11.02(9.56-12.50)$ & $<.001^{*}$ \\
\hline
\end{tabular}

STI sexually transmitted diseases; HIV human immunodeficiency virus

aMedian (interquartile range); "Statistical significance

$(\mathrm{HR}=5.17,95 \%$ CI 2.37-11.29), and trichomoniasis $(\mathrm{HR}=2.13,95 \%$ CI 1.34-3.38; Table 5). Subgroups based on gender revealed that female patients with bipolar disorder exhibited higher risks of subsequent syphilis
$(\mathrm{HR}=7.76,95 \%$ CI 1.86-32.43), genital warts $(\mathrm{HR}=5.46$, 95\% CI 2.13-14.03), and trichomoniasis ( $\mathrm{HR}=2.30,95 \%$ CI 1.44-3.67) than the matched female control subjects. However, male patients with bipolar disorder exhibited a 
Table 2: Number of newly diagnosed sexually transmitted diseases between bipolar disorder and control subjects which was stratified by follow-up duration

\begin{tabular}{|c|c|c|c|c|c|}
\hline \multirow{2}{*}{$\begin{array}{l}\text { Follow-up duration } \\
\text { (years) }\end{array}$} & \multicolumn{2}{|c|}{ Bipolar disorder } & \multicolumn{2}{|c|}{ Control cohort } & \multirow[b]{2}{*}{ Risk ratio $(95 \% \mathrm{CI})$} \\
\hline & $\begin{array}{l}\text { No. of HIV } \\
\text { infection }\end{array}$ & Per 1,000 person-years & No. of HIV infection & Per 1,000 person-years & \\
\hline Overall & 5 & 2.55 & 6 & 0.72 & $3.51(0.85-13.81)$ \\
\hline $0-1$ & 0 & 0 & 1 & 8.11 & $0.00(0.00-69.24)$ \\
\hline$\geq 1$ & 5 & 2.55 & 5 & 0.71 & $4.22(0.97-18.33)$ \\
\hline \multirow{2}{*}{$\begin{array}{l}\text { Follow-up duration } \\
\text { (years) }\end{array}$} & \multicolumn{2}{|c|}{ Bipolar disorder } & \multicolumn{2}{|c|}{ Control cohort } & \multirow{2}{*}{ Risk ratio $(95 \% \mathrm{CI})$} \\
\hline & No. of Syphilis & Per 1,000 person-years & No. of Syphilis & Per 1,000 person-years & \\
\hline Overall & 11 & 4.68 & 12 & 1.10 & $3.87(1.55-9.58)^{*}$ \\
\hline $0-1$ & 3 & 67.18 & 1 & 18.96 & $5.10(0.41-267.70)$ \\
\hline$\geq 1$ & 8 & 4.56 & 11 & 1.09 & $3.07(1.07-8.39)^{*}$ \\
\hline \multirow{2}{*}{$\begin{array}{l}\text { Follow-up duration } \\
\text { (years) }\end{array}$} & \multicolumn{2}{|c|}{ Bipolar disorder } & \multicolumn{2}{|c|}{ Control cohort } & \multirow[b]{2}{*}{ Risk ratio $(95 \% \mathrm{CI})$} \\
\hline & $\begin{array}{l}\text { No. of Genital } \\
\text { warts }\end{array}$ & $\begin{array}{c}\text { Per 1,000 person- } \\
\text { years }\end{array}$ & No. of Genital warts & Per 1,000 person-years & \\
\hline Overall & 14 & 7.08 & 13 & 1.40 & $4.55(1.98-10.50)^{*}$ \\
\hline $0-1$ & 1 & 6.97 & 0 & 0 & N/A \\
\hline$\geq 1$ & 13 & 7.08 & 13 & 1.40 & $4.23(1.80-9.89)^{*}$ \\
\hline \multirow{2}{*}{$\begin{array}{l}\text { Follow-up duration } \\
\text { (years) }\end{array}$} & \multicolumn{2}{|c|}{ Bipolar disorder } & \multicolumn{2}{|c|}{ Control cohort } & \multirow{2}{*}{ Risk ratio $(95 \% \mathrm{CI})$} \\
\hline & No. of Gonorrhea & Per 1,000 person-years & No. of Gonorrhea & Per 1,000 person-years & \\
\hline Overall & 8 & 1.89 & 23 & 1.31 & $1.47(0.57-3.40)$ \\
\hline $0-1$ & 1 & 37.10 & 2 & 34.92 & $0.89(0.02-17.13)$ \\
\hline$\geq 1$ & 7 & 1.83 & 21 & 1.29 & $1.41(0.51-3.43)$ \\
\hline \multirow{2}{*}{$\begin{array}{l}\text { Follow-up duration } \\
\text { (year) }\end{array}$} & \multicolumn{2}{|c|}{ Bipolar disorder } & \multicolumn{2}{|c|}{ Control cohort } & \multirow[b]{2}{*}{ Risk ratio $(95 \% \mathrm{CI})$} \\
\hline & $\begin{array}{c}\text { No. of Chlamydial } \\
\text { infection }\end{array}$ & Per 1,000 person-years & $\begin{array}{c}\text { No. of Chlamydial } \\
\text { infection }\end{array}$ & Per 1,000 person-years & \\
\hline Overall & 13 & 5.03 & 33 & 3.27 & $1.66(0.80-3.24)$ \\
\hline $0-1$ & 2 & 73.92 & 5 & 52.05 & $0.70(0.07-4.27)$ \\
\hline$\geq 1$ & 11 & 4.91 & 28 & 3.23 & $1.66(0.75-3.44)$ \\
\hline \multirow{2}{*}{$\begin{array}{l}\text { Follow-up duration } \\
\text { (year) }\end{array}$} & \multicolumn{2}{|c|}{ Bipolar disorder } & \multicolumn{2}{|c|}{ Control cohort } & \multirow[b]{2}{*}{ Risk ratio $(95 \% \mathrm{CI})$} \\
\hline & $\begin{array}{c}\text { No. of } \\
\text { Trichomoniasis } \\
\end{array}$ & Per 1,000 person-years & No. of Trichomoniasis & Per 1,000 person-years & \\
\hline Overall & 28 & 9.17 & 57 & 5.09 & $2.09(1.28-3.34)^{*}$ \\
\hline $0-1$ & 1 & 103.62 & 9 & 115.32 & $0.20(0.00-1.45)$ \\
\hline$\geq 1$ & 27 & 8.99 & 48 & 4.99 & $2.39(1.44-3.91)^{*}$ \\
\hline
\end{tabular}

HIV human immunodeficiency virus; CI confidence interval.

"Statistical significance.

higher risk than the matched male control subjects only for subsequent genital warts $(\mathrm{HR}=4.34,95 \%$ CI $1.11-17.01$; Table 6A and 6B).

\section{DISCUSSION}

In our work, the prevalence of STIs, including HIV infection $(0.39 \%)$, primary, secondary, and latent syphilis $(0.85)$, genital warts $(1.08 \%)$, gonorrhea $(0.62 \%)$, chlamydial infection (1.01\%), and trichomoniasis $(2.17 \%)$, in patients with bipolar disorder were demonstrated. Compared with previous studies regarding the prevalence of STIs in patients with mental disorders, the prevalence of STIs in the current study was relatively low. For example, a study surveying the prevalence of STIs in psychiatric outpatients revealed prevalence of gonorrhea, chlamydial infection, and trichomoniasis of $1 \%, 3.3 \%$, and $15.7 \%$, respectively [10]. Furthermore, prevalence rates of syphilis in patients with mental illness varied from $1.1 \%$ to $7.6 \%$ [19]. A study reported that over one-third of the sample (38\%) reported a lifetime history of one or more STIs in psychiatric outpatients [20]. There are two possible reasons for this discrepancy. First, underestimation of the prevalence of STIs in the current study should be 
Table 3: Analyses of risk factors for sexually transmitted diseases in patients with and without bipolar disorder

\begin{tabular}{lcccc}
\hline \multirow{2}{*}{ Predictive variables } & \multicolumn{2}{c}{ Univariate analysis } & \multicolumn{2}{c}{ Multivariate analysis } \\
\cline { 2 - 5 } Bipolar disorder & $2.29(1.73-3.04)$ & $<.001$ & $2.23(1.68-2.96)$ & $<.001^{*}$ \\
Age $(<40=1, \geq 40=0)$ & $1.41(1.01-1.84)$ & .013 & $1.23(0.93-1.65)$ & .153 \\
Gender $($ Female $=1$, Male $=0)$ & $2.36(1.76-3.16)$ & $<.001$ & $2.36(1.76-3.16)$ & $<.001^{*}$ \\
Comorbidities & & & & .144 \\
$\quad$ Hypertension & $0.63(0.43-0.93)$ & .019 & $0.73(0.47-1.12)$ & \\
$\quad$ Diabetes mellitus & $1.07(0.72-1.59)$ & .742 & & \\
Dyslipidemia & $0.71(0.46-1.07)$ & .100 & & \\
Coronary artery disease & $0.78(0.50-1.22)$ & .779 & & \\
Congestive heart failure & $0.85(0.32-2.28)$ & .743 & & .293 \\
Cerebrovascular disease & $0.66(0.37-1.15)$ & .141 & & $.047^{*}$ \\
Chronic pulmonary disease & $1.10(0.72-1.70)$ & .656 & & \\
Degree of urbanization & & & & \\
Urban & Reference & & & \\
Suburban & $0.81(0.59-1.10)$ & .175 & $0.85(0.62-1.12)$ & \\
$\quad$ Rural & $1.61(1.01-2.41)$ & .020 & $1.51(1.01-2.28)$ & \\
Income group & & & & \\
No income & Reference & & & \\
Low income & $1.10(0.77-1.58)$ & .595 & & \\
Medium income & $1.19(0.78-1.81)$ & .422 & & \\
High income & $0.73(0.42-1.30)$ & .284 & & \\
\hline
\end{tabular}

HR indicates hazard ratio; $\mathrm{CI}$ indicates confidence interval

considered. Because STIs may be asymptomatic, some patients with STIs may not have sought medical treatment and thus were not diagnosed. Moreover, patients with STIs may feel stigmatized because of their STIs and thus do not seek medical help. Second, most of previous studies results were based on cross-sectional study designs instead of a longitudinal design like our study.

In this study, we found that bipolar disorder was significantly associated with an increased sequential risk of STIs. There are several possible explanations for the increased risk of STIs in patients with bipolar disorder. First, impulsivity, hypersexuality, and impaired judgment are major symptoms of bipolar disorder, and these symptoms place patients with bipolar disorder at risk for STIs [21]. Second, a previous study demonstrated that patients bipolar disorder have high rates of risky sexual behaviors [22, 23]. For example, their compliance with contraceptive measures was poor [23]. Furthermore, they often engage in sex trading and are susceptible to engaging in coerced sex $[22,24]$. Third, behavioral addictions, including sex addiction, are more frequent in patients with bipolar disorder than in healthy control subjects and are related to higher impulsivity levels and immaturity [25]. In a study investigating sexual behavior in a population of psychiatric patients with schizophrenia, schizoaffective disorder, and bipolar disorder, the results showed that most of the patients engaged in sexual behavior putting them at high risk for acquisition and transmission of STIs [23]. Finally, substance use disorders are common comorbidities in patients with bipolar disorder [21], and previous work has demonstrated that substance abuse and dependence increase the risk of STIs [26-28].

A previous study showed that female gender is a risk factor for STIs in the general population [29]. Our study demonstrates that female gender, compared with male gender, is also a risk factor for acquisition of STIs in patients with bipolar disorder. Higher rates of sexually risky behaviors in female patients with bipolar disorder than in male patients with bipolar disorder might be a possible explanation for this finding. In a study summarizing research pertinent to the clinical care of women with bipolar disorder, the results showed that women with bipolar disorder are more likely than men with bipolar disorder to report sex trading, resulting in a higher risk for STIs in female patients with bipolar disorder [22]. Furthermore, a lack of female contraceptive devices also adds to the vulnerability of these patients [24].

In the present study, we conducted a subgroup analysis stratified according to the duration between the diagnosis of bipolar disorder and new-onset STIs (Table 
Table 4: Analyses of risk factors for sexually transmitted diseases in patients with bipolar disorder

\begin{tabular}{|c|c|c|c|c|}
\hline \multirow{2}{*}{ Predictive variables } & \multicolumn{2}{|c|}{ Univariate analysis } & \multicolumn{2}{|c|}{ Multivariate analysis } \\
\hline & HR $(95 \%$ CI $)$ & $P$ value & HR $(95 \%$ CI $)$ & $P$ value \\
\hline Age $(<40=1, \geq 40=0)$ & $1.13(0.72-1.78)$ & .600 & & \\
\hline Gender $($ Female $=1$, Male $=0)$ & $2.91(1.73-4.89)$ & $<.001$ & $2.36(1.77-3.16)$ & $<.001^{*}$ \\
\hline \multicolumn{5}{|l|}{ Comorbidities } \\
\hline Hypertension & $0.55(0.30-1.03)$ & .062 & $0.67(0.45-1.01)$ & .057 \\
\hline Diabetes mellitus & $0.54(0.25-1.18)$ & .125 & & \\
\hline Dyslipidemia & $0.47(0.22-1.03)$ & .060 & $0.80(0.52-1.25)$ & .327 \\
\hline Coronary artery disease & $0.75(0.37-1.50)$ & .411 & & \\
\hline Congestive heart failure & $0.43(0.06-3.10)$ & .403 & & \\
\hline Cerebrovascular disease & $0.66(0.30-1.44)$ & .300 & & \\
\hline Chronic pulmonary disease & $1.31(0.70-2.42)$ & .396 & & \\
\hline \multicolumn{5}{|l|}{ Degree of urbanization } \\
\hline Urban & Reference & & & \\
\hline Suburban & $0.65(0.37-1.14)$ & .131 & & \\
\hline Rural & $1.01(0.54-1.87)$ & .977 & & \\
\hline \multicolumn{5}{|l|}{ Income group } \\
\hline No income & Reference & & & \\
\hline Low income & $0.91(0.50-1.66)$ & .767 & & \\
\hline Medium income & $1.01(0.48-2.13)$ & .970 & & \\
\hline High income & $(0.48-2.66)$ & .786 & & \\
\hline
\end{tabular}

HR indicates hazard ratio; $\mathrm{CI}$ indicates confidence interval

Table 5: Hazard ratios of time until sexually transmitted diseases between bipolar disorder and control subjects during a ten-year follow-up period

\begin{tabular}{lcc}
\hline & Crude HR (95\% CI) & Adjusted HR (95\% CI) $^{\mathbf{a}}$ \\
\hline HIV infection & $3.53(1.08-11.55)^{*}$ & $2.58(0.73-9.11)$ \\
Syphilis & $3.85(1.70-8.73)^{*}$ & $3.99(1.72-9.28)^{*}$ \\
Genital warts & $4.57(2.15-9.73)^{*}$ & $5.17(2.37-11.29)^{*}$ \\
Gonorrhea & $1.46(0.65-3.25)$ & $0.94(0.41-2.16)$ \\
Chlamydial infection & $1.66(0.87-3.16)$ & $1.57(0.51-3.01)$ \\
Trichomoniasis & $2.08(1.32-3.27)^{*}$ & $2.13(1.34-3.38)^{*}$ \\
\hline
\end{tabular}

HIV human immunodeficiency virus; HR hazard ratio; CI confidence interval.

*Statistical significance; a Adjusted for age, gender, hypertension, diabetes mellitus, dyslipidemia, coronary artery diseases, congestive heart failure, chronic pulmonary diseases, cerebrovascular diseases, income and urbanization.

2). The results indicate that incident syphilis, genital warts, and trichomoniasis were increased beyond the first year following a bipolar diagnosis. Patients with bipolar disorder are likely to exhibit a higher frequency of outpatient and inpatient visits than the general population, leading to an earlier diagnosis of STIs, which cause surveillance bias. However, in our work, the risk ratio for the newly diagnosed syphilis, genital warts, and trichomoniasis did not increase within 1 year of bipolar diagnosis in the bipolar cohort. Moreover, when patients diagnosed with STIs within 1 year of bipolar diagnosis were excluded, the risk ratio for newly diagnosed syphilis, genital warts, and trichomoniasis remained high for the bipolar cohort, and the ratios were all statistically significant. This result suggests that the increased risks of syphilis, genital warts, and trichomoniasis in patients with bipolar disorder were not caused by surveillance bias.

This study has several strengths. First, our study design included an unbiased patient selection process. Because participation in the NHI is mandatory and 
Table 6A: Hazard ratios of time until sexually transmitted diseases between male patients with bipolar disorder and male control subjects during a ten-year follow-up period

\begin{tabular}{lcc}
\hline & Crude HR (95\% CI) & Adjusted HR (95\% CI) ${ }^{\mathbf{a}}$ \\
\hline HIV infection & $2.90 .(0.82-10.27)$ & $2.25(0.59-8.63)$ \\
Syphilis & $2.39(0.80-7.12)$ & $2.76(0.89-8.53)$ \\
Genital warts & $3.50(0.94-13.02)$ & $4.34(1.11-17.01)^{*}$ \\
Gonorrhea & $1.43(0.46-4.43)$ & $0.96(0.30-3.10)$ \\
Chlamydial infection & $0.94(0.20-4.35)$ & $0.73(0.14-3.73)$ \\
\hline
\end{tabular}

HIV human immunodeficiency virus; HR hazard ratio; CI confidence interval.

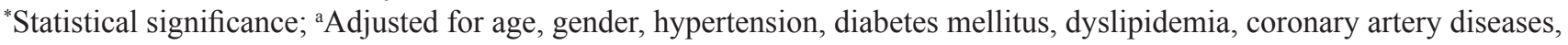
congestive heart failure, chronic pulmonary diseases, cerebrovascular diseases, income and urbanization.

Table 6B: Hazard ratios of time until sexually transmitted diseases between female patients with bipolar disorder and female control subjects during a ten-year follow-up period

\begin{tabular}{lcc}
\hline & Crude HR (95\% CI) & Adjusted HR (95\% CI) \\
\hline HIV infection & $1291.59(0.01-1.63 \mathrm{E} 18)$ & $83.20(0.01-1.29 \mathrm{E} 8)$ \\
Syphilis & $8.21(2.05-32.84)^{*}$ & $7.76(1.86-32.43)^{*}$ \\
Genital warts & $5.16(2.04-13.08)^{*}$ & $5.46(2.13-14.03)^{*}$ \\
Gonorrhea & $1.49(0.48-4.68)$ & $1.02(0.31-3.35)$ \\
Chlamydial infection & $1.90(0.93-3.88)$ & $1.88(0.91-3.88)$ \\
Trichomoniasis & $2.30(1.45-3.64)^{*}$ & $2.30(1.44-3.67)^{*}$ \\
\hline
\end{tabular}

HIV human immunodeficiency virus; HR hazard ratio; CI confidence interval.

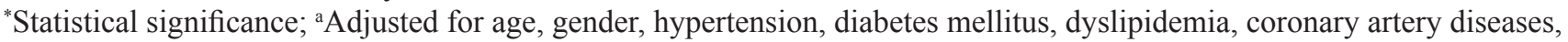
congestive heart failure, chronic pulmonary diseases, cerebrovascular diseases, income and urbanization.

all residents of Taiwan can access health care with low copayments, referral bias is low, and follow-up compliance is high. Second, our study is a populationbased study including large samples from all hospitals across the country. In studies with small samples or in single-hospital case studies, which are common in the relevant literature, it is difficult to develop such an index with high acceptability across the health care industry. Third, data used in this study were derived from the NHI system in Taiwan. As an observational database, these data reflect current real-world diagnostic patterns.

However, the present study has several limitations inherent in the use of claims databases that should be considered. First, the NHIRD does not provide detailed information on patients, such as number of sex partners, engaging in sex with promiscuous partners, and condom use. These are all significant risk factors for STIs. Thus, we were unable to control for these potentially confounding factors. Second, compared with previous studies regarding the prevalence of STIs in patients with mental disorders, the prevalence of STIs in the current study was relatively low. Underestimation of the prevalence of STIs in the current study should be considered. Third, information on the diagnostic accuracy and severity of bipolar disorder in the current study were unavailable. Whether the severity of bipolar disorder is related to STI development should be further evaluated.

In conclusion, this nationwide cohort study indicated an increased risk of syphilis, genital warts, and trichomoniasis among patients with bipolar disorder. Female gender is a risk factor for acquisition of STIs in patients with bipolar disorder. Taking a sexual history from persons with bipolar disorder is important, and patients engaging in high-risk sexual behavior should be routinely screened for STIs to enable detection, treatment, and preventive education. Furthermore, prospective studies, particularly those with additional patient-level data, are warranted to confirm our findings.

\section{PATIENTS AND METHODS}

\section{Data sources}

Established in 1995, the National Health Insurance (NHI) program is a mandatory health insurance program that offers comprehensive medical care coverage, including outpatient, inpatient, emergency, and traditional Chinese medicine, to all residents of Taiwan, with a coverage rate of up to $98 \%$ [30]. The NHI Research Database (NHIRD) contains comprehensive information 
regarding clinical visits, including prescription details and diagnosis codes based on the A code and International Classification of Diseases, Ninth Revision, Clinical Modification (ICD-9-CM). The NHIRD is managed and publicly released by the National Health Research Institutes (NHRI) for research purposes, and confidentiality is maintained according to the directives of the Bureau of NHI. The data source for our study was the Longitudinal Health Insurance Database 2000 (LHID 2000), which is a dataset included in the NHIRD. Data for the LHID was collected by systematically and randomly sampled from the NHIRD; this database includes the data of 1 million individuals. The NHRI reported no significant differences in sex distribution, age distribution, or average insured payroll-related amount between the patients in the LHID and those in the original NHIRD [31].

\section{Ethics statement}

The Institutional Review Board of Taichung Veterans General Hospital approved this study. Written consent from the study patients was not obtained because the NHI dataset consists of de-identified secondary data for research purposes and the Institutional Review Board of Taipei Veterans General Hospital issued a formal written waiver for the need for consent.

\section{Study population}

Using data extracted from the LHID 2000, we conducted a retrospective cohort study of patients who were newly diagnosed with bipolar disorder between January 1, 2000, and December 31, 2004. The patients with bipolar disorder were defined as meeting criteria for ICD-9-CM codes 296.0, 296.1, 296.4, 296.5, 296.6, $296.7,296.8,296.80$, or 296.89. We excluded patients who were diagnosed with bipolar disorder between January 1, 1996, and December 31, 1999. We also excluded patients who were diagnosed with STIs (HIV infection; primary, secondary, and latent syphilis; genital warts; gonorrhea; chlamydial infection; and trichomoniasis) before they were diagnosed with bipolar disorder. For each patient with bipolar disorder included in the final cohort, four ageand gender-matched control patients without STIs were randomly selected from the LHID 2000. All patients with bipolar disorder and all control subjects were observed until diagnosed with HIV infection (ICD-9-CM codes 042 or V08, A049); primary, secondary, and latent syphilis (ICD9-CM codes 091-097, A060); genital warts (ICD-9-CM code 078.11); gonorrhea (ICD-9-CM codes 098, A061); chlamydial infection (ICD-9-CM codes 078.8, 078.88); or trichomoniasis (ICD-9-CM codes 131, A079). If they did not meet any of these criteria, they were observed until death, withdrawal from the NHI system, or December 31, 2013. The primary clinical outcomes assessed were newly diagnosed HIV infection; primary, secondary, and latent syphilis; genital warts; gonorrhea; chlamydial infection; and trichomoniasis. Common comorbidities, including hypertension, diabetes mellitus, dyslipidemia, coronary artery disease, congestive heart failure, chronic pulmonary disease, and cerebrovascular disease, were also compared between patients with bipolar disorder and control subjects. Insurance premiums, calculated according to the beneficiary's total income, were used to estimate monthly income. Monthly income was grouped into no income, low income (monthly income $<20,000$ New Taiwan Dollar [NTD]), median income $(20,000 \mathrm{NTD} \leq$ monthly income $<$ 40,000 NTD), and high income (monthly income $\geq 40,000$ NTD). Urbanization was divided into three groups: urban, suburban, and rural. Urbanization and monthly income levels were used to represent socioeconomic status.

\section{Statistical analysis}

The primary outcomes in this study were occurrence of newly diagnosed HIV infection; primary, secondary, and latent syphilis; genital warts; gonorrhea; chlamydial infection; or trichomoniasis. We first compared the distribution of demographic characteristics between the patients with bipolar disorder and control subjects by using independent $t$-tests and chi-squared tests. To investigate potential surveillance bias, subgroups were stratified according to the duration of enrollment. In addition, a Cox proportional hazards regression model was used to identify the risk factors associated with STIs in the whole sample and among patients with bipolar disorder. Control variables, such as age; sex; common comorbidities, including hypertension, diabetes mellitus, dyslipidemia, coronary artery disease, congestive heart failure, chronic pulmonary disease, and cerebrovascular disease; urbanization; and monthly income were included as covariates in the univariate model. Factors that demonstrated a moderately significant statistical relationship in the univariate analysis $(P<.1)$ were entered by forward selection in a multivariate Cox proportional-hazards regression model. Furthermore, the Cox proportional hazards regression model was also constructed to calculate the hazard ratio (HR) of six different kinds of STIs, including HIV infection; primary, secondary, and latent syphilis; genital warts; gonorrhea; chlamydial infection; and trichomoniasis. Subgroups were also stratified according to gender to survey the risk of STIs of male and female subjects in the bipolar and control cohorts.

The SAS statistical software for Windows, Version 9.3 (SAS Institute, Cary, NC, USA), was used for data extraction, computation, linkage, processing, and sampling. All other statistical analyses were performed using the SPSS statistical software for Windows, Version 20 (IBM, Armonk, NY, USA). The results of comparisons with a $P$ value less than .05 were considered to indicate a statistically significant relationship. 


\section{Abbreviations}

STIs: sexually transmitted infections; HR: hazard ratio; CI: confidence interval; HIV: human immunodeficiency virus; NHI: national health insurance; NHIRD: national health insurance research database; ICD9-CM: International Classification of Diseases, Ninth Revision: Clinical Modification; NHRI: the National Health Research Institutes; LHID 2000: the Longitudinal Health Insurance Database 2000.

\section{Author contributions}

S-C Lee, L-Y Hu, and C-C Shen designed the protocol; C-K Hu and J-H Hung handled the data; C-K Hu, S-J Tsai, and A-C Yang analyzed the data; L-Y Hu, $\mathrm{M}-\mathrm{W}$ Huang, and C-C Shen wrote the original manuscript.

\section{ACKNOWLEDGMENTS}

The authors would like to thank the Research Center of Medical informatics at Kaohsiung Veterans General Hospital for technical assistance. The study is based on data from the National Health Insurance Research Database provided by the Bureau of National Health Insurance (BNHI) in Taiwan and managed by National Health Research Institutes (NHRI). We express our particular gratitude to the government organization BNHI and the non-profit foundation NHRI.

\section{CONFLICTS OF INTEREST}

The authors declare that they have no conflicts of interest.

\section{FUNDING}

The authors declare no funding sources were supported for the study.

\section{REFERENCES}

1. Jansen K, Magalhães PV, Tavares Pinheiro R, Kapczinski F, Silva RA. Early functional impairment in bipolar youth: a nested population-based case-control study. J Affect Disord. 2012; 142:208-12. https://doi.org/10.1016/j. jad.2012.04.028.

2. Samamé C, Martino DJ, Strejilevich SA. Longitudinal course of cognitive deficits in bipolar disorder: a metaanalytic study. J Affect Disord. 2014; 164:130-38. https:// doi.org/10.1016/j.jad.2014.04.028.

3. Cullen B, Ward J, Graham NA, Deary IJ, Pell JP, Smith DJ, Evans JJ. Prevalence and correlates of cognitive impairment in euthymic adults with bipolar disorder: A systematic review. J Affect Disord. 2016; 205:165-81. https://doi. org/10.1016/j.jad.2016.06.063.

4. Pompili M, Gonda X, Serafini G, Innamorati M, Sher L, Amore M, Rihmer Z, Girardi P. Epidemiology of suicide in bipolar disorders: a systematic review of the literature. Bipolar Disord. 2013; 15:457-90. https://doi.org/10.1111/ bdi.12087.

5. Merikangas KR, Akiskal HS, Angst J, Greenberg PE, Hirschfeld RM, Petukhova M, Kessler RC. Lifetime and 12-month prevalence of bipolar spectrum disorder in the National Comorbidity Survey replication. Arch Gen Psychiatry. 2007; 64:543-52. https://doi.org/10.1001/ archpsyc.64.5.543.

6. Guilbert JJ. The World Health Report 2006: working together for health. Educ Health (Abingdon). 2006; 19:38587. https://doi.org/10.1080/13576280600937911.

7. Diagnostic and Statistical Manual of Mental Disorders, 5. Washington, DC: American Psychiatric Association. 2013.

8. Wang H, Naghavi M, Allen C, Barber RM, Bhutta ZA, Carter A, Casey DC, Charlson FJ, Chen AZ, Coates MM, Coggeshall M, Dandona L, Dicker DJ, et al, and GBD 2015 Mortality and Causes of Death Collaborators. Global, regional, and national life expectancy, all-cause mortality, and cause-specific mortality for 249 causes of death, 1980-2015: a systematic analysis for the Global Burden of Disease Study 2015. Lancet. 2016; 388:1459-544. https:// doi.org/10.1016/S0140-6736(16)31012-1.

9. Owusu-Edusei K Jr, Chesson HW, Gift TL, Tao G, Mahajan $\mathrm{R}$, Ocfemia MC, Kent CK. The estimated direct medical cost of selected sexually transmitted infections in the United States, 2008. Sex Transm Dis. 2013; 40:197-201. https:// doi.org/10.1097/OLQ.0b013e318285c6d2.

10. King C, Feldman J, Waithaka Y, Aban I, Hu J, Zhang S, Hook E 3rd, Bachmann LH. Sexual risk behaviors and sexually transmitted infection prevalence in an outpatient psychiatry clinic. Sex Transm Dis. 2008; 35:877-82. https:// doi.org/10.1097/OLQ.0b013e31817bbc89.

11. Beyer JL, Taylor L, Gersing KR, Krishnan KR. Prevalence of HIV infection in a general psychiatric outpatient population. Psychosomatics. 2007; 48:31-37. https://doi. org/10.1176/appi.psy.48.1.31.

12. Himelhoch S, McCarthy JF, Ganoczy D, Medoff D, Dixon LB, Blow FC. Understanding associations between serious mental illness and HIV among patients in the VA Health System. Psychiatr Serv. 2007; 58:1165-72. https://doi. org/10.1176/ps.2007.58.9.1165.

13. Beyer J, Kuchibhatla M, Gersing K, Krishnan KR. Medical comorbidity in a bipolar outpatient clinical population. Neuropsychopharmacology. 2005; 30:401-04. https://doi. org/10.1038/sj.npp.1300608.

14. Prince JD, Walkup J, Akincigil A, Amin S, Crystal S. Serious mental illness and risk of new HIV/AIDS diagnoses: an analysis of Medicaid beneficiaries in eight 
states. Psychiatr Serv. 2012; 63:1032-38. https://doi. org/10.1176/appi.ps.201100342.

15. Hariri AG, Karadag F, Gokalp P, Essizoglu A. Risky sexual behavior among patients in Turkey with bipolar disorder, schizophrenia, and heroin addiction. J Sex Med. 2011; 8:2284-91. https://doi. org/10.1111/j.1743-6109.2011.02282.x.

16. Meade CS, Graff FS, Griffin ML, Weiss RD. HIV risk behavior among patients with co-occurring bipolar and substance use disorders: associations with mania and drug abuse. Drug Alcohol Depend. 2008; 92:296-300. https:// doi.org/10.1016/j.drugalcdep.2007.07.013.

17. Brown LK, Hadley W, Stewart A, Lescano C, Whiteley L, Donenberg G, DiClemente R, and Project STYLE Study Group. Psychiatric disorders and sexual risk among adolescents in mental health treatment. J Consult Clin Psychol. 2010; 78:590-97. https://doi.org/10.1037/ a0019632.

18. Bakare MO, Agomoh AO, Ebigbo PO, Onyeama GM, Eaton J, Onwukwe JU, Okonkwo KO. Co-morbid disorders and sexual risk behavior in Nigerian adolescents with bipolar disorder. Int Arch Med. 2009; 2:16. https://doi. org/10.1186/1755-7682-2-16.

19. Campos LN, Guimarães MD, Carmo RA, Melo AP, Oliveira HN, Elkington K, McKinnon K. HIV, syphilis, and hepatitis $\mathrm{B}$ and $\mathrm{C}$ prevalence among patients with mental illness: a review of the literature. Cad Saude Publica. 2008 (Suppl 4); 24:s607-20. https://doi.org/10.1590/ S0102-311X2008001600012.

20. Vanable PA, Carey MP, Carey KB, Maisto SA. Differences in HIV-related knowledge, attitudes, and behavior among psychiatric outpatients with and without a history of a sexually transmitted infection. J Prev Interv Community. 2007; 33:79-94. https://doi.org/10.1300/J005v33n01_07

21. Özcan NK, Boyacıoğlu NE, Enginkaya S, Dinç H, Bilgin H. Reproductive health in women with serious mental illnesses. J Clin Nurs. 2014; 23:1283-91. https://doi. org/10.1111/jocn.12332.

22. Miller LJ, Ghadiali NY, Larusso EM, Wahlen KJ, AvniBarron O, Mittal L, Greene JA. Bipolar disorder in women. Health Care Women Int. 2015; 36:475-98. https://doi.org/1 $0.1080 / 07399332.2014 .962138$.
23. Raja M, Azzoni A. Sexual behavior and sexual problems among patients with severe chronic psychoses. Eur Psychiatry. 2003; 18:70-76. https://doi.org/10.1016/ S0924-9338(03)00009-9.

24. Coverdale JH, Bayer TL, McCullough LB, Chervenak FA. Sexually transmitted disease prevention services for female chronically mentally ill patients. Community Ment Health J. 1995; 31:303-15. https://doi.org/10.1007/BF02207518.

25. Di Nicola M, Tedeschi D, Mazza M, Martinotti G, Harnic D, Catalano V, Bruschi A, Pozzi G, Bria P, Janiri L. Behavioural addictions in bipolar disorder patients: role of impulsivity and personality dimensions. J Affect Disord. 2010; 125:82-88. https://doi.org/10.1016/j.jad.2009.12.016.

26. Zenilman JM, Hook EW 3rd, Shepherd M, Smith P, Rompalo AM, Celentano DD. Alcohol and other substance use in STD clinic patients: relationships with STDs and prevalent HIV infection. Sex Transm Dis. 1994; 21:220-25. https://doi.org/10.1097/00007435-199407000-00008.

27. Tetrault JM, Fiellin DA, Niccolai LM, Sullivan LE. Substance use in patients with sexually transmitted infections: results from a national U.S. survey. Am J Addict. 2010; 19:504-09. https://doi. org/10.1111/j.1521-0391.2010.00087.x.

28. Cook RL, Clark DB. Is there an association between alcohol consumption and sexually transmitted diseases? A systematic review. Sex Transm Dis. 2005; 32:156-64. https://doi.org/10.1097/01.olq.0000151418.03899.97.

29. Liu H, Li X, Stanton B, Liu H, Liang G, Chen X, Yang $\mathrm{H}$, Hong Y. Risk factors for sexually transmitted disease among rural-to-urban migrants in China: implications for HIV/sexually transmitted disease prevention. AIDS Patient Care STDS. 2005; 19:49-57. https://doi.org/10.1089/ apc.2005.19.49.

30. Wu CY, Chen YJ, Ho HJ, Hsu YC, Kuo KN, Wu MS, Lin JT. Association between nucleoside analogues and risk of hepatitis B virus-related hepatocellular carcinoma recurrence following liver resection. JAMA. 2012; 308:1906-14. https://doi.org/10.1001/2012.jama.11975.

31. National Health Insurance Research Database. National Health Research Institutes (http://english.nhri.org.tw/ NHRI_WEB/nhriw001Action.do). 